\title{
KAFKA: UM ENCONTRO ENTRE JOSEPH K. E O PROCESSO DISCIPLINAR PREVISTO NA LEI ESTADUAL 6.536/73.
}

\author{
Marcelo Almeida Sant'Anna ${ }^{1}$
}

\begin{abstract}
RESUMO: A análise de institutos jurídicos a partir da Literatura proporciona perspectivas diferenciadas, principalmente quando se estrutura o pensamento crítico levando em conta autores que estimulam a reflexão, tais como Kafka. Inserido neste diálogo, verifica-se que o processo administrativo-disciplinar apresenta irregularidades, na medida em que o princípio constitucional do devido processo legal, por exemplo, resta violado. Em que pese existam dificuldades, observa-se que a Constituição permite superar antigas concepções, abrindo caminho para interpretações constitucionais, estribadas nos direitos e garantias fundamentais.
\end{abstract}

Palavras-chave: Processo Administrativo - Constituição - Literatura

\section{Apresentações e cumprimentos: as preliminares de um encontro}

Os encontros reservam oportunidades interessantes para trocas de experiências; pessoas diferentes, em um único momento, têm a oportunidade de partilhar emoções e sentimentos. No entanto, o que dizer quando há o encontro entre duas projeções da inteligência humana, como o Direito e a Literatura? Cada qual com uma linguagem, com objetos distintos e com métodos diferentes. Mesmo que produzidos pelas mãos humanas, esses saberes não possuem emoções, podem reproduzi-las, mas nunca terão a verdadeira capacidade do sentir, pois, lhes falta a condição essencial da carne. Nesse ponto, não basta a inteligência ou a subjetividade que todo ser humano possui. Sentir exige muito mais do que isso, exige o arranjo criador da matéria, exige as dezenas de milhares de células que compõem nosso corpo. Então, se não podem sentir, o que restaria para se partilhar, perguntaria o literato?

O Direito, certamente, não fica imune à Literatura, da mesma forma que essa não fica imune ao Direito. Tal encontro empresta ao Direito a melodia da poesia e graça da prosa, já a Literatura se enclausura - temporariamente - nas fórmulas sombrias que os textos legais impõem que somente um grupo restrito de iniciados tem o poder de decifrar. Partilha-se, então, métodos e características.

\footnotetext{
${ }^{1}$ Advogado, Mestre em Ciências Criminais pela PUCRS e Especialista em Ciências Penais pela UFRGS.
} 
Nesse ponto, já se sente o efeito embriagante das palavras, as quais, contaminadas pela singularidade do encontro, não mantêm mais a sobriedade das formas jurídicas. Tal desrespeito pela metodologia científica só se justifica em momentos como esse, de liberdade, de poesia, nos quais a metodologia não é do Direito, não é da Literatura, não é das Letras, é apenas do encontro. Contudo, o que diria Joseph K. sobre a beleza desse encontro, quando o Direito, representado pelo processo, se mostra incompreensível? Deveria ele reproduzir o mesmo diálogo inicial que manteve com inspetor que lhe comunicou sobre sua prisão e o avisou sobre a desnecessidade de constituir um advogado? ${ }^{2}$

A forte crítica ao sistema judicial da época, cuidadosamente articulada por Kafka através de seu personagem, encontra - de certa forma - cores na atualidade. Diferente daquelas pinturas que com o tempo perdem as cores, a obra, hoje, revela arranjos mais fortes do que outrora, atualizando a crítica do escritor. Em contrapartida, ao se ajustar o foco, percebe-se avanços importantes, de sorte que as conquistas da humanidade também reclamam justiça e, sendo assim, deve-se dizer que da mesma maneira que a obra se mostra exuberante em cores, quando se olha todo o caminho percorrido pelo pensamento ocidental, o texto fica pálido, composto apenas por diversos tons de cinza. A narrativa de Kafka deixa os processualistas inquietos, pois, poderia ferir de morte justamente uma das mais importantes conquistas do Iluminismo ${ }^{3}$ : o processo. Todavia, por mais ásperas e atuais que sejam as palavras do autor, não se pode deixar de reconhecer que o processo ainda é uma das mais relevantes invenções do pensamento jurídico ocidental.

A rigor nenhum meio de solução de conflitos é perfeito, até porque a perfeição seria a sua desnecessidade, no entanto, toda crítica que se produz contra o processo, não lhe causa

\footnotetext{
2 "K. olhou fixamente para o inspetor. Deveria agora aprender lições de civilidade com um homem provavelmente mais jovem do que ele? Ser repreendido pela sua franqueza? E quanto ao motivo e à autoridade que determinavam sua detenção, não deveria saber nada!? Presa de certa irritação, começou a andar de um lado para outro - ninguém o impediu; arrumou os punhos, mexeu no peito da camisa, passou a mão pelo cabelo e ao passar pelos três rapazes disse: - Isto é um verdadeiro absurdo! - o que os fez olharem-no com simpatia, mas circunspectos. Por fim tomou posição em frente à mesa do inspetor. Hasterer, meu advogado, é meu amigo íntimo - disse-lhe. - Posso telefonar para ele? - Certamente - replicou o inspetor -, mas não vejo bem qual a utilidade disso, a não ser que tenha algum negócio particular a tratar. - E qual seria a utilidade disso? - gritou K., mais espantado do que exasperado. - Afinal, que espécie de homem é o senhor? Pede-me que seja sensato e comporta-se do modo mais insensato que se possa imaginar! Isso é surpreendente! Primeiro me caem em cima em minha própria casa, depois ficam à minha volta o tempo todo, esgotando-me a paciência! Qual poderia ser a utilidade de um advogado, quando me dizem que estou preso? Pois bem, não telefonarei." (KAFKA, Franz. O Processo. Tradução de Manuel Paulo Ferreira. São Paulo: Círculo do Livro, s.d. p. 16-17.)

${ }^{3}$ Impossível deixar de lembrar dos ensinamentos de GILISSEN: "O século XVIII é o <Século das Luzes>, da <Aufklärung>. É o século em que a Europa é francesa pela Cultura, Artes, Letras, Filosofia. São inúmeros os pensadores e escritores deste século cuja influência foi considerável e persistente sobre factos e sobre o pensamento tanto político como jurídico do século XIX e até do século XX. As ideias de soberania da nação, isto é, soberania do povo, de separação de poderes, de preponderância da lei, da legalidade das infrações e das penas, de direitos do homem, direitos naturais e subjectivos inalienáveis, tomaram corpo no século XVIII; expressão do liberalismo nascente, estas ideias dominaram desde então a concepção do direito e do Estado. O Bill of Rights em Inglaterra em 1689, as constituições dos Estados americanos em 17761777, a constituição federal dos Estados Unidos em 1787, a Declaração francesa dos Direitos do Homem e as constituições da época da Revolução $(1791,1793,1795)$, actos legislativos ainda hoje em vigor direta ou indiretamente, transpuseram estas ideias políticas e filosóficas para a realidade jurídica." (GILISSEN, John. Introdução Histórica ao Direito. Tradução de A. M. Hespanha e L. M. Macaísta Malheiros. 2. ed. Lisboa: Fundação Calouste Gulbenkian, 1995. p. 366-367.)
} 
ferida alguma - muito pelo contrário - aponta apenas suas imperfeições e indica o melhor caminho para um ideal utópico de justiça e paz. Aliás, uma afirmação como essa, só seria possível nesse improvável encontro. ${ }^{4}$

Deixando o maneirismo sedutor que os primeiros olhares tendem a produzir, o Direito revela sua intenção. Por mais graça e melodia que tenham as palavras do literato, o treinamento e a prepotência do Direito tendem a afastar a bela arte e exigem a delimitação de um objeto. Assim, perplexidade e a incompreensão de Joseph K. não podem passar desapercebidas, mormente, quando se observa tais sentimentos na atualidade. Dessa forma, pede-se vênia à Literatura para, a partir da incompreensão Joseph K., analisar certos dispositivos da legislação institucional do Ministério Público do Estado do Rio Grande do Sul.

Pretende-se demonstrar as irregularidades do processo administrativo-disciplinar previsto na Lei Estadual 6.536/73 ${ }^{5}$. Tal esforço se justifica pela relevância da Instituição, na medida em que o Ministério Público - enquanto função essencial à Justiça - deveria zelar pela Constituição e sua eficácia material. Contudo, a sua legislação interna corporis revela graves distorções, incompatíveis com um processo disciplinar constitucional.

\section{O racionalismo que entristece a melodia}

Noticiado um fato passível de adequação típica disciplinar, a Corregedoria-Geral do Ministério Público requisita informações ao promotor de justiça envolvido. Logo após as informações, é elaborado um parecer por um dos promotores-corregedores, opinando pela instauração de expediente disciplinar ou não; esse parecer, então, é submetido ao CorregedorGeral, o qual possui atribuição funcional para instaurar procedimento administrativodisciplinar através de portaria.

Essa é uma das formas de iniciar o processo administrativo-disciplinar. Certamente, esse artigo não irá esgotar o assunto, sua relevância se estabelece não pela crítica, mas pelo desejo de construir um procedimento verdadeiramente constitucional. Por essa razão, a abordagem será mais enfática nos pontos sensíveis sob a perspectiva da Carta de 1988.

Dito isso, observa-se quatro questões fundamentais: (1) o Corregedor-Geral - através de ato administrativo discricionário - nomeia os promotores-corregedores; (2) o Corregedor-

\footnotetext{
${ }^{4}$ Quando a mente se abre à Literatura as utopias surgem, descompromissadas do rigor científico, colocando o jurista em situação delicada: pensar e não dizer ou dizer e depois se arrepender?

${ }^{5}$ Nossa análise leva em conta as modificações introduzidas pela Lei Estadual 11.735/2002 e seguintes.
} 
Geral delimita o objeto da imputação administrativa; (3) o Corregedor-Geral, através dos promotores-corregedores, preside a instrução, deferindo ou indeferindo provas; (4) a defesa técnica do acusado, ao final da instrução, fala nos autos antes do promotor-corregedor.

As questões 1 e 2 , isoladamente ${ }^{6}$, não revelam qualquer problema, muito pelo contrário, tem-se que estão ajustadas. Depois de eleito pelo Colégio de Procuradores, deve o Corregedor-Geral se cercar de membros com plena capacidade técnica e bom discernimento, de maneira a compor uma equipe de trabalho eficiente. Da mesma forma, a imputação administrativa é de atribuição do Corregedor-Geral, cabendo a esse delimitar os contornos do tipo administrativo disciplinar. Entretanto, não se pode dizer o mesmo nas questões 3 e 4 . Explica-se:

O rompimento de uma ordem constitucional e a introdução de uma nova constituição desencadeia uma série de consequências, não só pelo fato de que boa parte do ordenamento jurídico não será recepcionado, mas também porque exige uma profunda mudança da cultura jurídica há muito consolidada. No entanto, determinadas instituições - tendo em vista sua atribuição constitucional - devem de pronto adaptar sua regulamentação à nova ordem. Então, o Ministério Público, enquanto Instituição essencial à Justiça ${ }^{7}$ tem a missão constitucional de defender a ordem jurídica, a começar pela Constituição, e de adaptar sua legislação interna corporis aos dispositivos constitucionais.

Dessa maneira, não se pode colocar no mesmo prato da balança o Parquet e os demais órgãos do Poder Executivo, mesmo que se esteja tratando de funções exclusivamente administrativas. Isso porque a administração pública em geral não foi investida das mesmas atribuições constitucionais. Aliás, essa equiparação diminuiria a importância institucional do Ministério Público.

A relevância do debate se percebe quando da constatação de que diversas normas administrativas aplicáveis ao Parquet estão em oposição à Constituição de 1988 e têm equivocadamente - sua constitucionalidade ratificada administrativamente. Trata-se, pois, de verificar a possibilidade de o Ministério Público poder declarar - na sua esfera administrativa - a inconstitucionalidade de determinada norma. Veja-se:

Dispõe o artigo 151 e artigo 153 da Lei 6.536/73:

\footnotetext{
${ }^{6}$ Se diz "isoladamente" porque esses pontos, em conjunto aos demais dispositivos, determinam grave inconstitucionalidade e cerceamento de defesa, conforme será demonstrado a seguir. Então, não pode olvidar que todos os pontos delineados estão conectados.

${ }^{7}$ Art. 127. O Ministério Público é instituição permanente, essencial à função jurisdicional do Estado, incumbindo-lhe a defesa da ordem jurídica, do regime democrático e dos interesses sociais e individuais indisponíveis.
} 
Art. 151 - Encerrada a instrução, o acusado poderá requerer novas diligências em 48 (quarenta e oito) horas e, findo esse prazo, terá vista dos autos para alegações escritas, no prazo de 5 (cinco) dias.

$[\ldots]$

Art. 153 - Apresentadas as alegações finais, ou não, e findo o respectivo prazo, a autoridade processante, dentro de 10 (dez) dias, elaborará o relatório conclusivo, no qual especificará, quando cabível, as disposições legais transgredidas e as sanções aplicáveis, devendo propor, também, quaisquer outras providências que lhe parecerem necessárias.

Há flagrante afronta aos princípios máximos do contraditório, da ampla defesa e do devido processo legal ${ }^{8}$.

Fruto da construção Iluminista e com o objetivo fundamental de servir de instrumento para limitar o exercício do poder ${ }^{9}$, é da essência do processo - e está diretamente ligada à sua finalidade - oportunizar que a pessoa acusada fale por último, sempre. Nesse ponto, não se pode ignorar que a Corregedoria funciona como verdadeiro órgão de acusação, conforme exaustivamente já determinado na jurisprudência administrativa do Ministério Público. A rigor, à Corregedoria se garante poderes muito superiores ao de uma simples parte, pois, além de definir o objeto da imputação, preside toda a instrução e a coleta das provas, o que ocorre através dos promotores-corregedores, esses nomeados a critério exclusivo do Corregedor-Geral.

Não bastasse isso, assegura-se ao Corregedor-Geral legitimidade recursal, bem como assento no Conselho Superior do Ministério Público e no Órgão Especial do Colégio de Procuradores na qualidade de membro, ainda que não possa votar nos procedimentos disciplinares ${ }^{10}$. Então, a Corregedoria, nos procedimentos disciplinares, apresenta-se como um "sujeito processual", investido de amplos poderes. ${ }^{11}$

O promotor de justiça eventualmente acusado, por sua vez, tem apenas seu procurador, o qual deverá postular ao Corregedor-Geral a produção das provas que entender pertinentes e aguardar o deferimento ou não; todavia, ao final do procedimento, deverá -

\footnotetext{
${ }^{8}$ Art. $5^{\circ}$ [...] LIV - ninguém será privado da liberdade ou de seus bens sem o devido processo legal;

LV - aos litigantes, em processo judicial ou administrativo, e aos acusados em geral são assegurados o contraditório e ampla defesa, com os meios e recursos a ela inerentes; (grifou-se)

9 Vide: CINTRA, Antonio Carlos de Araújo, GRINOVER, Ada Pellegrini, DINAMARCO, Cândido Rangel. A Instrumentalidade do Processo. 3. ed. São Paulo: Malheiros, 1993. p. 27.

${ }^{10}$ Lei 7.669/82. Art. 10 - O Órgão Especial do Colégio de Procuradores será composto pelos doze Procuradores de Justiça mais antigos no cargo e por doze Procuradores de Justiça eleitos pelos demais, para um mandato de dois anos, além do Procurador-Geral de Justiça, seu Presidente, que terá voto qualificado, e do Corregedor-Geral do Ministério Público, estes membros natos. [...]

Art. 11 - O Conselho Superior do Ministério Público, com atribuição de fiscalizar e superintender a atuação do Ministério Público, bem como a de velar pelos seus princípios institucionais, compõe-se do Procurador-Geral de Justiça, seu Presidente, do Corregedor-Geral do Ministério Público, estes membros natos, e de nove Procuradores de Justiça que não estejam afastados da carreira.

Art. 13. [...] $\S 2^{\circ}$ - O Corregedor-Geral do Ministério Público não terá direito a voto, nas sessões do Órgão Especial do Colégio de Procuradores e do Conselho Superior do Ministério Público, nos procedimentos disciplinares.

${ }^{11}$ Certamente, não se ignora o conceito clássico de angularização processual, todavia, a referência serve como ilustração da perspectiva e da relação processual que se estabelece.
} 
ainda - submeter toda sua argumentação antecipadamente ao "órgão da acusação". Com a devida vênia, a desigualdade de "armas" parece evidente, pois, o relatório do promotorcorregedor certamente irá rebater tese por tese, argumento por argumento, ponto por ponto... Exaustivamente e por escrito.

Por fim, no dia do julgamento pelo Conselho Superior do Ministério Público, ao Corregedor-Geral se asseguram 20 minutos para a sustentação oral da portaria e, da mesma forma, se concedem 20 minutos à defesa técnica também para sustentação oral. Contudo, mesmo que se realize um trabalho brilhante da tribuna, o prejuízo à defesa persistirá, uma vez que parte do tempo será dedicada para contrapor os argumentos também deduzidos da tribuna pelo Corregedor-Geral e o tempo restante para rebater um relatório escrito.

O prejuízo, então, manifesta-se de várias maneiras; primeiro, pela quebra da ordem lógica dos eventos processuais; segundo, porque se garante também ao Corregedor-Geral tempo de sustentação oral; e terceiro, porque há diferença de meios, na medida em que o relatório escrito foi antecipadamente avaliado pelo relator e revisor, permitindo-lhes tempo necessário para a reflexão, ao passo que os argumentos defensivos proferidos na tribuna exigem a decisão imediata, sem olvidar que o sistema romano-germânico, por tradição, é mais escrito do que falado e, de acordo com essa característica, fomos todos lapidados.

Em prosseguimento, a Corregedoria - diante de casos concretos - manifestou-se no sentido de manter essa situação, fundamentando a impossibilidade de agir diferente nos atributos do ato administrativo vinculado e dizendo, em apertada síntese, que para a inversão ou modificação do procedimento se exige provimento judicial específico.

Entende a Corregedoria que não lhe cabe modificar o procedimento, o qual somente poderia ser alterado via ação judicial. Miguel Reale, diferentemente, defende não só a possibilidade, mas o dever de a administração negar cumprimento a leis inconstitucionais:

O executivo tem o 'poder-dever' de recusar a aplicação às leis manifestamente inconstitucionais, cabendo-lhe, nesse ponto, o benefício da inexecução por vício de inconstitucionalidade, sem a necessidade de anterior manifestação do Poder Judiciário. [...] Se o próprio particular pode recusar cumprimento a uma determinação legal eivada de inconstitucionalidade, sujeitando-se às consequências desse seu entendimento, afigura-se-me incompreensível que se persevere em recusar-se ao Governo igual prerrogativa, máxime em se tratando do exercício de um dos três Poderes do Estado. A recusa na execução de um preceito legal, que conflite com dispositivos constitucionais, entra no quadro geral da tutela da legalidade, ou, poder-se-ia mesmo dizer que constitui uma das formas do 'poder de polícia' no tocante à defesa 
impostergável da ordem constitucional, que deve ser preservada contra tudo e contra todos, inclusive contra os abusos do legislador ordinário. ${ }^{12}$

Trata o autor de hipótese de promulgação de lei contrária a constituição, a qual “nasce” com vício insuperável. No mesmo sentido de REALE, sustenta MONTEIRO:

\begin{abstract}
Como a lei inconstitucional não é lei, não obrigando, portanto, a ninguém ou como uma lei inconstitucional é lei apenas aparentemente, já que, de fato, não o é, não existindo de direito, ou ainda, é para o direito como se nunca houvesse existido, considera-se irrecusável a conclusão de que o Chefe do Poder Executivo não está obrigado ao cumprimento de leis inconstitucionais. [...] a lei inconstitucional é absolutamente nula, ou mais exatamente, é inexistente, já que jamais produziu efeito algum. ${ }^{13}$
\end{abstract}

Hely Lopes Meirelles, por sua vez, em sua obra editada em vida e sem as atualizações post mortem, sustentou:

O cumprimento de leis inconstitucionais tem suscitado dúvidas e perplexidade na doutrina e na jurisprudência, mas vem-se firmando o entendimento - a nosso ver exato - de que o Executivo não é obrigado a acatar normas legislativas contrárias à Constituição ${ }^{14}$

Não se trata, dessa forma, da possibilidade de a administração declarar a inconstitucionalidade da lei retirando-a do ordenamento jurídico, mas de negar os efeitos indesejáveis que a lei inconstitucional poderia emanar, viciando os atos administrativos. Nesse trilho, acredita-se que exista consenso na afirmação de que a administração pode anular atos administrativos considerados inconstitucionais, em atenção - também - ao princípio da legalidade; então, com mais razão não deveria a administração praticar atos administrativos sabidamente inconstitucionais, tais como a abertura de prazo para alegações finais antes do relatório conclusivo pelo promotor-corregedor.

Modernamente, a doutrina mais qualificada caminha no rumo indicado nesse artigo, de sorte que o ensinamento de MATTOS esclarece parte da discussão:

Por esse princípio entendemos que o Relatório levado a efeito pelos membros da Comissão Disciplinar, que se constitui nas razões finais do referido trio processante, deveria oportunizar ao servidor acusado que o mesmo se

\footnotetext{
${ }^{12}$ REALE, Miguel. Revogação e Anulamento do Ato Administrativo. Rio de Janeiro: Forense, 1968. p. 46-47. Ainda, em parecer ao governo de São Paulo (DOE 19.03.1963, p. 7-8) orientou o Governador que determinasse a todos os órgãos administrativos que recusassem o cumprimento de determinada norma reputada inconstitucional, a qual era objeto do parecer.

13 MONTEIRO, Ruy Carlos de Barros. O argumento de inconstitucionalidade e o repúdio da lei pelo Poder Executivo. In: Revista Forense. v. 284. out-nov-dez. 1983. Rio de Janeiro: Forense, 1983. p. 102-103. No mesmo sentido: MASAGÃO, Mário. Curso de Direito Administrativo. 5. ed. Revista dos Tribunais, 1974. p. 147. Diz o autor em síntese que todos os Poderes têm a missão de guardiões da Constituição, no exato âmbito de sua esfera de atribuições.

${ }^{14}$ MEIRELLES, Hely Lopes. Direito Municipal Brasileiro. v. 2. 2. ed. São Paulo: Revista dos Tribunais, 1964. p. 514.
} 
manifestasse após a feitura e publicidade do respectivo Relatório, em respeito ao princípio do contraditório e da ampla defesa. ${ }^{15}$

E complementa o autor dizendo:

Tem-se, portanto, que os princípios do contraditório, do devido processo legal e da ampla defesa, estabeleceram regras jurídicas para as partes, que possuem o direito de exporem suas razões livremente, com a produção de todos os meios de provas em direito admitidos, na busca de estabelecer a verdade real dos fatos que estão sendo apurados.

$\mathrm{O}$ cerceamento de defesa possui o caráter de nulificar toda a apuração disciplinar, em decorrência de que o princípio é justamente o inverso, visto que o processo administrativo disciplinar não é mais inquisitório.

Possui o acusado o direito de se defender da melhor e mais ampla forma que houver, sem ser cerceado ou obstado dessa prerrogativa. ${ }^{16}$

Nota-se que toda criação Iluminista nem sempre coloca luz nas fendas escuras do sistema jurídico. Em pese tenhamos avançado para um processo constitucional, nossa realidade demonstra que os preceitos máximos nem sempre atingem os patamares inferiores do ordenamento. Os argumentos defendidos por MATTOS, a nosso ver irrefutáveis, não são plenamente aceitos por determinados setores, os quais - dentro a dialética jurídica - buscam razões para justificar sua (o)posição, mas sem negar a Constituição diretamente. Essa injustificável resistência, que se socorre das formas jurídicas, caracteriza certa posição política; pensamento que se mostra refratário à Carta de 1988. Talvez - e nesse ponto a Literatura me permite especular, pois a criação e a coragem de expor seus dizeres são suas mais belas características - tais posições jurídicas se expliquem pela nossa tradição arbitrária, profundamente marcada por sucessivos períodos de Exceção. ${ }^{17}$

\footnotetext{
${ }^{15}$ MATTOS, Mauro Roberto Gomes de. Tratado de Direito Administrativo Disciplinar. Rio de Janeiro: Forense, 2010. p. 87. ${ }_{16}^{16}$ MATTOS, Mauro Roberto Gomes de. Tratado de Direito Administrativo Disciplinar. Rio de Janeiro: Forense, 2010. p. 90.

${ }^{17}$ A formação de nosso Estado-Nação se deu a partir da Exceção, justamente quando D. Pedro dissolveu a primeira assembleia constituinte, pois, essa desejava diminuir seus poderes a ampliar as ideias liberais vigentes na Europa. RODRIGUES deixa evidente a divisão ideológica entre os dois grupos políticos da época, um monárquico e escravagista e ou outro republicano e liberal: "Além da corrente representada por José Bonifácio, o processo de independência contou, ainda, com a presença de outras tendências. O grupo organizado em torno de Joaquim Gonçalves Ledo e do Senado da Câmara do Rio de Janeiro refletia, em seu ideário, um liberalismo mais radical. Quando Ledo apresentou proposta no sentido de introduzir o voto direto nas eleições constituintes e, logo em seguida, o juramento prévio à Carta Magna que seria elaborada, ficou evidente a posição de seu grupo: impor a soberania da nação ao seu imperante. José Bonifácio manobrou no sentido de excluir tal possibilidade, consoante sua visão política: um pacto constitucional no qual as prerrogativas monárquicas estariam acima da nação e imunes à instabilidade intrínseca dos conflitos ideológicos e doutrinários" (RODRIGUES, Celso. Tradição e modernidade na formação do Estado-Nação brasileiro: a assembléia constituinte de 1823. 1998. Dissertação (Mestrado em História)-Instituto de Filosofia e Ciências Humanas, Pontifícia Universidade Católica do Rio Grande do Sul, Porto Alegre, 1998. p. 74-75). A queda do Império e a introdução da república não foi capaz de criar um ambiente estável, tolerante e constitucional, conforme ensina ROSA: "Analisando a história republicana do país podemos dizer que os intervalos democráticos, quando não acompanhados de decretos de "estado de sítio", foram sucedidos por ditaduras: poucos anos separam o governo de Washington Luís da ditadura do "Estado Novo" (que vigorou de 1937 até 1945). No curto "intervalo democrático", entre os anos de 1945 a 1964, as investidas militares com intenções golpistas foram constantes: 1945, Getúlio Vargas retirou-se do poder sob ameaça de ser deposto; em 1954, o mesmo Vargas recebeu um comunicado do Exército para renunciar sob ameaça de intervenção militar - seu suicídio adiou a intervenção. A renúncia de Jânio Quadros em 1961 propiciou outra tentativa militar, só dissuadida pela influência da campanha pela "Legalidade" e com a concordância de João Goulart em assumir a Presidência da República sob a forma parlamentarista. Nesse caso, o ordenamento jurídico foi alterado para garantir a manutenção desse mesmo ordenamento." (ROSA, Susel Oliveira da. Estado de exceção e vida nua: violência
}

\section{E S U C A}




\section{Despedidas: acenos, abraços e promessa de retorno}

Então, a perplexidade de Joseph K. em relação ao processo e suas fórmulas - por vezes incompreensíveis - é reescrita na atualidade, ilustrada pelos casos concretos judiciais ou administrativos; de maneira que a literatura de Kafka causa desconforto ao jurista; as palavras do autor afrontam o pensamento jurídico, mancham a engrenagem intelectual que faz o sistema funcionar e criticam o resultado da produção legislativa.

Certamente, Joseph K. não entenderia como uma das principais Instituições da Justiça pode conviver com procedimentos que restringem as garantias constitucionais. A perplexidade de Mr. K. é idêntica a dos promotores de justiça eventualmente processados administrativamente, os quais sentem o efeito paralisante da surpresa e da incompreensão.

Mas é necessário que o barco retorne ao seu porto seguro, portanto, nada melhor do que repetir o que foi dito ao início: as críticas não ferem o processo ou a Instituição, pelo contrário, têm o poder do renascimento. Tal como o fogo que transforma a Fênix em cinzas, as críticas desse artigo, justificadas pela paixão das utopias, têm o calor da transformação e da vida e não o frio da morte.

\section{REFERÊNCIAS BIBLIOGRÁFICAS}

CINTRA, Antonio Carlos de Araújo, GRINOVER, Ada Pellegrini, DINAMARCO, Cândido Rangel. A Instrumentalidade do Processo. 3. ed. São Paulo: Malheiros, 1993.

GILISSEN, John. Introdução Histórica ao Direito. Tradução de A. M. Hespanha e L. M. Macaísta Malheiros. 2. ed. Lisboa: Fundação Calouste Gulbenkian, 1995.

KAFKA, Franz. O Processo. Tradução de Manuel Paulo Ferreira. São Paulo: Círculo do Livro, s.d.

MASAGÃO, Mário. Curso de Direito Administrativo. 5. ed. Revista dos Tribunais, 1974.

MATTOS, Mauro Roberto Gomes de. Tratado de Direito Administrativo Disciplinar. Rio de Janeiro: Forense, 2010.

policial em Porto Alegre entre os anos 1960 e 1990. 2007. Tese (Doutorado em História)-Instituto de Filosofia e Ciências Humanas, UNICAMP, Campinas, 2007. p. 42.)" 
MEIRELLES, Hely Lopes. Direito Municipal Brasileiro. v. 2. 2. ed. São Paulo: Revista dos Tribunais, 1964.

MONTEIRO, Ruy Carlos de Barros. O argumento de inconstitucionalidade e o repúdio da lei pelo Poder Executivo. In: Revista Forense. v. 284. out-nov-dez. 1983. Rio de Janeiro: Forense, 1983.

REALE, Miguel. Revogação e Anulamento do Ato Administrativo. Rio de Janeiro: Forense, 1968.

RODRIGUES, Celso. Tradição e modernidade na formação do Estado-Nação brasileiro: a assembléia constituinte de 1823. 1998. Dissertação (Mestrado em História)-Instituto de Filosofia e Ciências Humanas, Pontifícia Universidade Católica do Rio Grande do Sul, Porto Alegre, 1998.

ROSA, Susel Oliveira da. Estado de exceção e vida nua: violência policial em Porto Alegre entre os anos 1960 e 1990. 2007. Tese (Doutorado em História)-Instituto de Filosofia e Ciências Humanas, UNICAMP, Campinas, 2007. 